\title{
La conducta omisiva en el delito de colusión
}

\section{Omissive conduct in the crime of collusion}

\author{
Michael Ángelo Alvarez Yaguillo
}

\begin{abstract}
Resumen: el autor desarrolla la problemática que surge con relación al delito de colusión, en sus modalidades simple y agravada, en cuanto a su posible configuración a través de conductas omisivas; omisión propia y omisión impropia; para tal fin, se abordará la tipicidad objetiva del delito de colusión, seguidamente se desarrollará el contenido de las modalidades omisivas del delito, es decir, la omisión propia y la omisión impropia o también denominada comisión por omisión, para luego desarrollar propiamente la problemática planteada en el presente trabajo, haciendo un recorrido de las posiciones adoptadas por la doctrina y jurisprudencia nacionales, y finalmente esbozar las razones que nos permitan afirmar que el delito en cuestión no puede configurarse mediante conductas omisivas.
\end{abstract}

Abstract: the author develops the problem that arises in relation to the crime of collusion, in its simple and aggravated forms, in terms of its possible configuration through omissionate behaviors; proper omission and improper omission; For this purpose, the objective typicity of the crime of collusion will be addressed, then the content of the omission modalities of the crime will be developed, that is, the own omission and the improper omission or also called commission by omission, to then properly develop the problem raised in the present work, making a tour of the positions adopted by the national doctrine and jurisprudence, and finally outlining the reasons that allow us to affirm that the crime in question cannot be configured through omissionate conducts.

Palabras clave: Derecho Penal - Colusión - Omisión propia - Omisión impropia.

Key words: Criminal Law - Collusion - Proper omission - Improper omission.

[*] Abogado por la Universidad Nacional de San Antonio Abad del Cusco, con estudios de Maestría en Derecho Penal y Procesal Penal y actualmente cursando estudios Doctorado en Derecho en la misma casa de estudios. Especialista en litigios sobre delitos económicos y contra la administración pública. Gerente General en Estudio Álvarez Abogados, Asesor del Departamento de Derecho Penal y Procesal Penal del Centro de Investigación de Estudiantes de Derecho - CIED. 


\section{INTRODUCCIÓN}

La configuración del delito de colusión, entendido como uno de los principales tipos penales de los denominados delitos de corupción de funcionarios, no presenta mayores dificultades cuando nos encontramos frente a conductas comisivas a la hora de efectuar las operaciones interpretativas del tipo penal para su correspondiente aplicación.

Sin embargo, ello no sucede cuando nos encontramos frente a conductas que, contrariamente a las primeras, no se encuentran representadas por el despliegue de una acción; conductas que se conocen como omisiones, y que se configuran ante el incumplimiento de una norma preceptiva que exige una determinada conducta, o aquellas que, por la situación especial en la que se encuentra el sujeto, este se encuentra obligado a garantizar que no ocurra un resultado lesivo.

Es así que, estos cuestionamientos planteados en la dogmática penal y que se ven reflejados día a día en la casuística, será abordada en el presente trabajo, para lo cual se iniciará con la identificación de los elementos propios de la conducta tipificada como delito de colusión, así como respecto a la figura de la omisión, propia e impropia, y de esta manera analizar la problemática que surge cuando se plantea la posibilidad de que una conducta omisiva configure el tipo penal de colusión, sea en su modalidad simple o agravada, para finalmente formular una postura concreta sobre el particular, que permita afirmar o negar esta posibilidad.

\section{EL DELITO DE COLUSIÓN}

\subsection{Generalidades}

Partiendo por la definición esbozada por el diccionario de la Real Academia de la Lengua Española, por colusión se entiende: «acción y efecto de coludir, pactar en daño a tercero" (Real Academia Española [RAE], s.f.); en las le- gislaciones, el delito de colusión ha merecido muchas denominaciones, así de forma tautológica, a criterio de Salinas (2019), los términos «colusión ilegal» o «colusión desleal» (p. 345), en opinión de Rojas (2002): "colusión fraudulenta" (p. 176); en otras legislaciones como el Código Penal de la República de Chile (1874), se encuentra tipificado dentro del capítulo de fraudes y exacciones ilegales (art. 239), en el Código Penal de la Nación Argentina (1991) se encuentra dentro del delito de negociación incompatible en el cargo (art. 265). En este sentido, adoptaremos el término de colusión, para los fines del presente trabajo, que por lo demás, constituye la denominación empleado mayoritariamente en la literatura, al menos peruana, sobre la materia.

\subsection{Regulación legislativa del delito de colusión}

El delito de colusión desleal se encuentra tipificado en el artículo 384 del Código Penal del Perú (1991), que originalmente contenía el siguiente texto:

El funcionario o servidor público que, en los contratos, suministros, licitaciones, concurso de precios, subastas o en cualquier otra operación semejante en la que intervenga por razón de su cargo o comisión especial defrauda al Estado o empresa del Estado o sociedades de economía mixta u órganos sostenidos por el Estado, concentrándose con los interesados en los convenios, ajustes, liquidaciones o suministros, será reprimido con pena privativa de libertad no menor de tres ni mayor de quince años. (art. 384)

A mérito de no pocas modificaciones, pasando incluso por la declaración de inconstitucional de una de estas, e incorporaciones de penas accesorias, se tiene a la fecha el siguiente texto normativo:

El funcionario o servidor público que, interviniendo directa 0 indirectamente, por razón de su cargo, en cualquier etapa de 
las modalidades de adquisición o contratación pública de bienes, obras o servicios, concesiones o cualquier operación a cargo del Estado concierta con los interesados para defraudar al Estado o entidad u organismo del Estado, según ley, será reprimido con pena privativa de libertad no menor de tres ni mayor de seis años; inhabilitación a que se refieren los incisos 1, 2 y 8 del artículo 36 , de cinco a veinte años; $y$, con ciento ochenta a trescientos sesenta y cinco días-multa.

El funcionario o servidor público que, interviniendo directa o indirectamente, por razón de su cargo, en las contrataciones y adquisiciones de bienes, obras o servicios, concesiones o cualquier operación a cargo del Estado mediante concertación con los interesados, defraudare patrimonialmente al Estado o entidad u organismo del Estado, según ley, será reprimido con pena privativa de libertad no menor de seis ni mayor de quince años; inhabilitación a que se refieren los incisos 1, 2 y 8 del artículo 36, de cinco a veinte años; y, con trescientos sesenta y cinco a setecientos treinta días-multa. La pena será privativa de libertad no menor de quince ni mayor de veinte años; inhabilitación a que se refieren los incisos 1, 2 y 8 del artículo 36 , de naturaleza perpetua, y, con trescientos sesenta y cinco a setecientos treinta días-multa, cuando ocurra cualquiera de los siguientes supuestos:

1. El agente actúe como integrante de una organización criminal, como persona vinculada o actúe por encargo de ella.

2. La conducta recaiga sobre programas con fines asistenciales, de apoyo o inclusión social o de desarrollo, siempre que el valor del dinero, bienes, efectos o ganancias involucrados supere las diez unidades impositivas tributarias.

3. El agente se aproveche de una situación de calamidad pública o emergencia sanitaria, o la comisión del delito comprometa la defensa, seguridad o soberanía nacional. (Código Penal, 1991)

\subsection{Contenido del tipo objetivo}

A fin de poder arribar al tema central del presente trabajo, corresponde verificar la tipicidad de este delito, siendo relevante abordar solo el análisis de la tipicidad objetiva.

\section{a) Sujeto activo}

Tratándose de un delito contra la administración pública, cometido por funcionario público, el sujeto activo del delito será siempre un funcionario o servidor público, conceptos que se equiparan en materia penal en nuestro ordenamiento jurídico penal (Código Penal, 1991).

La condición de funcionario no basta para que un sujeto pueda ser considerado autor de este delito, porque además de ello, deberá ostentar un deber específico; en esta línea interpretativa, autorizada doctrina nacional sostiene que «no basta dicha calidad para tener por realizado el injusto penal, dado que es necesario contar con una competencia normativa específica para intervenir en los procesos de contratación pública» (Castillo, 2017, p. 146).

Dado que el tipo penal sanciona un pacto o acuerdo colusorio, es necesario que se verifique no solamente la participación del funcionario público, sino que se identifique la intervención del interesado, quien no es otro que el administrado que participa en la contratación o en las operaciones estatales; este interesado, denominado también como extraneus, no podrá responder a título de autor, al no ostentar función pública, por lo que el título de imputación que le corresponde es la de cómplice primario.

\section{b) Sujeto pasivo}

Estando a la sistemática contemplada en el Código Penal, el Estado es el afectado por este delito. En efecto, para la consecución de sus objetivos, las diversas entidades del Estado, como los Gobiernos Regionales, las Municipalidades, los hospitales, las universidades, el propio Poder Judicial y Ministerio Público, entre otras, requieren celebrar contratos, así 
como realizar operaciones de naturaleza económica, situaciones en las que sus funcionarios pueden concertar con los terceros interesados con la finalidad de defraudar a la entidad.

\section{c) Bien Jurídico}

En palabras de Salinas (2019): «el delito de colusión al ser uno de infracción de deber, el bien jurídico genérico es el normal y recto funcionamiento de la Administración Pública que es manifestación material del Estado» (p. 361); asimismo, se da especial relevancia a las funciones que el funcionario público debe realizar, cuyo incorrecto desempeño constituye precisamente la lesión al bien jurídico protegido (Cáceres, 2016)

Al respecto, algunos autores, como Abanto (2003), sostienen que «el bien jurídico específico de este delito viene a ser el patrimonio del Estado (p. 261); desde una óptica crítica, Salinas (2019) afirma que el patrimonio vendría a ser el objeto del delito, mas no así el bien jurídico por no tratarse de un delito contra el patrimonio».

En este sentido, podemos concluir que el patrimonio estatal per se, no puede ser considerado como el bien jurídico de especial protección de este delito, pues más allá de confundirse con el objeto del delito, bien podría equipararse a otros delitos como el peculado y la malversación de fondos donde también se ve afectado el patrimonio del Estado, o a la vez, podría liar indebidamente los conceptos de bien jurídico y objeto del delito.

\section{d) La concertación}

El tipo penal del delito de colusión, previsto y sancionado en el artículo 384 del Código Penal, tipifica la conducta representada por el verbo rector de «concertar». El Diccionario de la Real Academia Española define al verbo «concertar» como «acordar el precio de algo», «pactar, ajustar, tratar o acordar un negocio» (Real Academia Española [RAE], s.f.); doctrina nacional hace referencia a la conjunción de la conducta del funcionario con la conducta del contratista, en cuyo encuentro se configura la concertación, la cual siempre debe tener una finalidad defraudatoria del Estado (Castillo, 2017; Reátegui, 2015), por su parte, nuestra jurisprudencia estableció que la conducta del sujeto activo "determina un alejamiento del agente respecto a la defensa de los intereses públicos que le están encomendados, y de los principios que informa la actuación administrativa". (Corte Suprema, R.N. N. ${ }^{\circ}$ 1296-2007-Lima)

De este modo, en cuanto al sujeto activo del delito, se distinguen al funcionario público y al extraneus, entre quienes se configura el acuerdo colusorio, determinando que el delito de colusión sea uno de convergencia, o denominado también «delito de encuentro, o pluripersonal» (Castillo, 2017, p. 239); distinguiéndose de los denominados delitos monosubjetivos donde «el tipo penal solo puede ser realizado por un individuo en calidad de autor» (Villavicencio, 2006, p. 308), en este sentido, será necesaria la participación de un funcionario y un tercero interesado para que pueda configurarse la concertación.

La concertación constituye el principal elemento de la conducta ilícita que sanciona el delito de colusión, pues es de esta forma que surge el pacto o acuerdo subrepticio entre el funcionario y el extraneus, y es a raíz de esta concertación que se vulnera el bien jurídico tutelado; por otro lado, como se advirtió precedentemente, la literatura no establece cómo deba realizarse este acuerdo, pudiendo representarse de distintas formas, ahora bien, esta amplitud de posibilidades conlleva a plantearse si es que pueda existir la concertación a través de conductas omisivas y si una omisión impropia puede equipararse a una concertación, temas que se desarrollarán en la última parte del presente trabajo.

\section{e) La defraudación}

Autorizada doctrina nacional sostiene que «defraudar, estafar o timar al Estado significa el quebrantamiento del rol especial asumido por el agente y la violación del principio de con- 
fianza depositado» (Rojas, 2002, p. 281); ahora bien, la concurrencia de este elemento será distinto en las modalidades del delito de colusión.

En la modalidad simple del delito de colusión, la defraudación a la que hace referencia el primer párrafo del artículo 384 del Código Penal «no constituye un elemento objetivo del tipo, sino un elemento tendencia». (García y Castillo, 2008, p. 28).

En cuanto a la modalidad agravada del delito de colusión, se tiene que al ser su nota característica la defraudación, «el concepto de defraudare o timar al Estado significa engaño al interés público y, como consecuencia de ello, un efectivo perjuicio patrimonial al erario público». (Salinas, 2019, p. 351)

Siendo ello así, compartimos el criterio que refiere que la afectación sobre los intereses del Estado se verificará objetivamente a través de un perjuicio de naturaleza patrimonial, por más que se trate de forzar dicha comprobación a través de otros mecanismos no necesariamente patrimoniales (Reátegui, 2015), de esta forma no sería posible afirmar que la modalidad agravada se configura por un perjuicio potencial, si fuere ello así, la conducta podría subsumirse en la modalidad simple.

\section{LOS DELITOS DE OMISIÓN}

\subsection{Concepto}

Debemos partir indicando que la dogmática ha diferenciado el concepto general de omisión del concepto que interesa al derecho penal, así, Mezger (1958) ya sostenía que el hecho de omisión no consiste en un «simple no hacer», sino en un no hacer algo». (p. 118).

A fin de conceptualizar el contenido de los delitos omisivos, podemos partir por afirmar que los delitos de comisión activa, contienen normas de prohibición, que en su tipificación se formulan en sentido positivo «el que mata a otro«, mientras que los delitos de omisión contienen normas preceptivas, cuya fórmula legal se representa en sentido negativo «el que no auxilia a otro»; por ello se evidencia que, en las primeras, la infracción jurídica consiste en la realización de la conducta prohibida, mientras que en las segundas, al ordenarse una acción concreta, la infracción jurídica consiste en la omisión de ese hacer.

En este sentido, el desarrollo dogmático ha distinguido con claridad dos tipos o clases de conductas omisivas penalmente relevantes, Jescheck postuló la existencia de delitos de "omisión propia» (delicta omissiva) y delitos de «omisión impropia» (delicta comissiva per omissionem) (1996/2014, p. 903); Mezger (1958) denominó a unos como «simple omisión» (delito de omisión), y a otros como omisión que produce el resultado (delito comisivo mediante omisión) (p. 118); siendo así, pese a la diversa terminología empleada por varios autores, se pueden distinguir claramente sus notas características. Por otro lado, Silva (2004) proponiendo una tripartición de los delitos de omisión agrega a los anteriores los que denomina «delitos de omisión agravados no idénticos a la comisión activa» (p. 653), sin embargo, como nos narra Villavicencio (2006), citando a Bacigalupo «algunos autores motivados por la teoría negativa de la acción que propone que la posición de garante es un elemento común de los delitos de comisión y omisión, se origina una tendencia al abandono de su diferenciación» (p. 652). Asimismo, citando a Jakobs, se afirma que, desde otra perspectiva, la conducta comisiva y la omisiva encuentra un punto de distinción en la medida que los deberes del ciudadano tengan origen, en un ámbito personal o bien en un ámbito institucional (Villavicencio, 2006). Por todo ello, para los fines del presente artículo se desarrollarán los dos primeros tipos o clases de delito omisivo que ha postulado la dogmática de forma mayoritaria.

\subsection{La omisión propia}

En palabras de, Mezger (1958), en estos delitos «no se castiga el no hacer de la acción esperada y exigida como tal, no siendo nece- 
sario un resultado» (p. 118); Por su parte Muñoz y García (2002) afirmaban que los delitos de omisión propia ya contienen un mandato; por ello, «los delitos de omisión propia son delitos de mera actividad» (p. 240). En base a lo anterior, esta modalidad de la conducta omisiva se encontrará regulada de forma expresa en un determinado tipo penal, por lo que el delito se tendrá por configurado cuando la conducta desplegada por el sujeto no guarde correlación con el supuesto de hecho descrito en la norma. (Villavicencio, 2006); asimismo, no será necesaria la concurrencia de un resultado para que la conducta sea calificada como típica; así como ejemplo se tiene el delito de omisión de socorro, que no exige la materialización de un menoscabo en el bien jurídico vida o integridad física de la víctima, sino la sola materialización de que el agente no le prestó auxilio.

\subsection{La omisión impropia}

En la literatura, existen varias denominaciones para referirse a este tipo de delito, así, Parma (2017) apunta que esta modalidad «lo que se supone es que el autor hace algo dejando de cumplir con el deber exigido, así la omisión impropia requiere que el autor tenga respecto de la víctima un contrato o por la acción previa (p. 428).

En la actualidad también se hace referencia al «deber de vigilancia de una fuente de peligros» (Villavicencio, 2006, p. 657); como se verá, el delito de omisión impropia va más allá de la sola verificación de la no realización de la conducta ordenada en un tipo penal, pues esta modalidad del delito omisivo responde a la configuración de resultados lesivos a bienes jurídicos protegidos por el derecho penal a través de conductas omisivas, por lo que precisamente debido al resultado, es que valorativamente se equipara a una conducta comisiva.

En efecto, a diferencia de la omisión propia, estos delitos no se encuentran tipificados en un tipo penal que contenga una norma preceptiva y cuya redacción se exprese en la no realización de una conducta esperada, sino, que se configuran en tipos penales de conductas comisivas que contienen mandatos de prohibición, empero que por la especial situación jurídica en que se encuentra el agente, tiene el deber de actuar de determinada forma; en este sentido los delitos de omisión impropia se alejan de los delitos de omisión propia, en la medida que los primeros precisan la verificación de un resultado lesivo al bien jurídico, pudiendo equipararlas a los delitos de resultado.

Se afirma que «los delitos de omisión impropia se encuentran tipificadas en tipos penales abiertos» (Villavicencio, 2006, p. 660), ello quedaría establecido debido a que «al requerir el Juez, que a través de una labor interpretativa, pueda ser llenado, con la búsqueda de elementos que fundamenten la especial situación jurídica del agente, denominado mayoritariamente posición de garante» (Jescheck y Weigend, 1996/2014, p. 913), en este sentido, se denotan los esfuerzos en la dogmática que se han realizado para buscar un factor de determinación de estas conductas, alegándose la concurrencia de una afectación del principio de legalidad, sin embargo, varias legislaciones, como la nuestra, han incorporado normas en la parte general de sus cuerpos normativos penales que introducen esta posibilidad de comisión de delitos, así, en nuestro vigente Código Penal, esta modalidad de omisión se encuentra tipificada en su artículo 13.

En este orden de ideas, en la literatura aún se encuentran problemas con el mandato de determinación, pues no existe una fuente legal del concepto de garante, ni existen criterios unificados para una descripción más completa, por ello, en el presente trabajo comentaremos sobre estos dos elementos para tratar de determinar el contenido de los delitos de omisión impropia: la posición de garante y la cláusula de correspondencia. 


\section{a) Posición de garante}

Uno de los paradigmas de la dogmática penal ha sido la determinación de las características que debe cumplir determinada situación para considerar que una persona ha de garantizar la protección de un bien jurídico evitando la realización de resultados lesivos; para explicar ello, surgió la teoría formal del deber jurídico, o llamada también teoría formal de la posición de garante, la cual estableció las fuentes para la determinación de la posición de garante, encontrando así a la ley, el contrato y el actuar precedente peligroso, añadiéndose posteriormente la estrecha relación vital (Villavicencio 2006).

Sin embargo, esta teoría fue ampliamente criticada por centrarse únicamente en la forma como puede originarse esta situación jurídica, mas no así no pregonar criterios materiales para su distinción, dándose lugar a la teoría material o de las funciones, o también denominada teoría de las funciones o material de la posición de garante, donde se postulan dos categorías: el deber de garante que desarrolla una función de protección para un bien jurídico determinado, denominado como «deberes de custodia» y aquellos otros que obligan al garante a la supervisión de una fuente de peligro, que vendrían a constituir «deberes de aseguramiento o de dominio» (Villavicencio, 2006).

Esta teoría, al igual que la primera, no estuvo exenta de críticas, así se concluyó que ambas deben ser tomadas en cuenta a la par, dado que la teoría formal del deber jurídico permite distinguir la fuente que la origina, mientras que la teoría material permite dotar de criterios sustanciales para la determinación de dichas fuentes.

Por lo demás, cabe mencionar que nuestro actual ordenamiento jurídico estableció como uno de los elementos de la modalidad omisiva de los delitos de comisión a la denominada posición de garante, así, se sancionará la conducta omitida por un sujeto «si tiene el deber jurídico de impedirlo o si crea un peligro inminente que fuera propio para producirlo» (Código Penal, 1991, art. 13.1)

\section{b) La cláusula de correspondencia}

Este elemento, en un inicio, fue considerada como la relación de causalidad que debe existir entre el resultado y la omisión del agente, posteriormente, dada la naturaleza de la omisión, al no precisar la materialización de un proceder que modifique el exterior como ocurre con las conductas comisivas, se entendió que no es posible exigir una causalidad física, propia de las ciencias naturales, por ello se desarrollo la denominada «causalidad hipotética» la misma que puede interpretarse, «aplicando la equivalencia de las condiciones: si se agrega mentalmente la acción mandada y el resultado desaparece, quiere decir que la omisión es causa» (Villavicencio, 2006, p. 671).

Sin embargo, ya se había establecido que «la ausencia del injusto de acción no puede ser compensada a través de una valoración global de hecho pues conduciría a una puesta en peligro de la seguridad jurídica» (Jescheck y Weigend, 1996/2014, p. 944); es así que, para dar solución a las limitaciones de la causalidad hipotética, se postuló la denominada cláusula de correspondencia, la cual va más allá de una mera causalidad natural para lograr establecer la correspondencia entre la conducta omisiva y su equiparación con una conducta activa (Pariona, 2017).

Con relación al fundamento de la cláusula de correspondencia se puede afirmar sobre la existencia de una equivalencia jurídica o valorativa más allá de una simple equivalencia formal (Villavicencio, 2006); del mismo modo se resalta la conveniencia de esta fórmula de equiparación por razones de política criminal (Hurtado, 2005); sin perjuicio de todo ello, encontramos que la denominada cláusula de correspondencia ha sido positivizada en nuestro ordenamiento sustantivo, al establecer que el sujeto que posee una posición de garante será sancionado por la concurrencia de un resultado lesivo «si su omisión corresponde a la realización del tipo penal mediante un hacer» (Código Penal, 1991, art. 13²). 


\section{LA CONDUCTA OMISIVA EN EL DELITO DE COLUSIÓN}

\subsection{Introducción a la problemática}

\section{a) Delimitación del objeto de análisis}

Habiendo desarrollado las bases necesarias para entender adecuadamente la problemática que representa la posibilidad de que se pueda configurar el delito de colusión a través de conductas omisivas, corresponde desarrollar en primer término la posición que adopta la doctrina nacional, para luego hacer un recorrido de la postura que adopta la Corte Suprema en su jurisprudencia y finalmente se esbozará una posición propia, justificando las razones que la sustentan.

Asimismo, se debe precisar que, con relación a la conducta omisiva que pretendemos desarrollar, el presente análisis corresponderá a uno de naturaleza sustantiva, dejando de lado aspectos relativos al derecho probatorio, propios del derecho procesal, como la posibilidad de que algunos actos u omisiones puedan ser constitutivos de hechos indiciarios a fin de acreditar mediante un juicio de inferencia lógica una concertación.

\section{b) La conducta típica en el delito de colusión}

De los conceptos postulados en nuestra dogmática nacional, y en atención al texto vigente del artículo 384 del Código Penal, la conducta incriminada en el tipo penal de colusión, sea que nos encontremos frente a la modalidad simple o agravada, está representada por el acuerdo colusorio, descrita bajo el verbo rector "concertar», que como se vio anteriormente «describe la conducta de dos partes: por un lado, la conducta del funcionario público y, por otro lado, la conducta del contratista» (Castillo, 2017, p. 232).

En este sentido, la conducta típica que configura el delito en cuestión se verifica a través de la concertación entre el funcionario público y el tercero interesado, donde se produce «la conjunción de voluntades con la fina- lidad de defraudar al ente público» (Reátegui, 2015 , p. 367). En este orden de ideas podemos concluir que la configuración del delito de colusión tiene lugar mediante el despliegue de voluntades del funcionario público y del extraneus, donde cada uno dirige su voluntad, materializada a través de sus correspondientes conductas, concurriendo en una conducta de encuentro: el pacto o acuerdo colusorio, distinguiéndose la imposibilidad de que se pueda configurar con el actuar de un solo sujeto, pues no se trata de un delito monosubjetivo.

De igual forma, en la modalidad agravada que exige un resultado lesivo para el Estado a través del verbo «defraudar», se tiene claro que la sola defraudación no configura por sí misma la modalidad agravada del delito de colusión, ello en la medida que el tipo penal ha establecido un medio comisivo: concertar, vale decir, que no será calificada como colusión agravada todo tipo de defraudación al Estado, sino solo aquella que se haya producido mediante una concertación entre el funcionario con vinculación funcionarial y el particular.

Tener clara esta premisa nos permitirá establecer adecuadamente la naturaleza de la conducta tipificada como delito de colusión, identificándola como un delito de encuentro o de convergencia, a efectos de analizar su correspondencia mediante actos omisivos, como se verá más adelante.

Finalmente, debe distinguirse la problemática en la posible o no configuración de este delito mediante conductas omisivas, con la materialización de un acuerdo colusorio, debidamente establecido, a través de conductas activas y omisivas, es decir, que nos encontremos frente a un acuerdo colusorio donde como parte de las ventajas indebidas que el funcionario ha de realizar a favor del particular, se compromete a dejar de revisar determinados requisitos, o a no realizar el cobro de penalidades por incumplimiento, entre otros, los cuales como puede verse son actos que materializaron un acuerdo colusorio previo formado entre ambos sujetos. 


\subsection{Posición de la doctrina nacional}

\section{a) Tesis a favor}

En primer término, cabe citar a Rojas (2002), quien afirma que «la colusión desleal también puede verificarse por actos de omisión» (p. 288), postura que como veremos más adelante es muy criticada por varios autores que decantan en la imposibilidad de que una conducta omisiva pueda configurar el delito de colusión.

Por su parte, Reategui (2015), comentando el delito en cuestión y abordando la problemática desarrollada en el presente trabajo, parte su fundamentación utilizando de forma analógica el caso en el delito de homicidio, donde a mérito de la cláusula de correspondencia la conducta activa consistente en matar se equipararía a una conducta omisiva «dejar morir», manifestando luego que en el delito de colusión dicha equivalencia se presentaría, en primer lugar, cuando «el funcionario con vinculación funcional no impide que otro funcionario al que le ha delegado facultades concierte fraudulentamente en los contratos, suministros, etc., con los interesados» y cuando «el funcionario con vinculo funcional no impide -en dicho contexto de concertación o negociación-que los intereses patrimoniales del Estado se vean mermados en beneficio de intereses particulares» (p. 403).

Asimismo, el referido autor, concluye planteando que, en los supuestos que acontecen en los procesos de selección, se equiparan a conductas comisivas aquellas omisiones dolosas del funcionario que facilite o permita que otros funcionarios sostengan un acuerdo colusorio con los particulares, con el ánimo de defraudar al Estado (Reátegui, 2015).

De lo expuesto, se puede verificar que la postura adoptada por estos autores no logran justificar cómo podría concurrir propiamente la cláusula de correspondencia en el delito de colusión, pese a que se postula como ejemplo, a modo de analogía, el delito de homicidio, donde se logra equiparar la conducta «matar» a «dejar morir», no se logra determinar entonces cuál sería la conducta omisiva que habría de equipararse a la «concertación», pues solo se hace referencia a un eventual «dejar que se defraude", sin considerar que dicha defraudación deberá originarse, precisamente, a través de una concertación.

\section{b) Tesis en contra}

En cuanto a la postura que niega la posibilidad de que el delito de colusión pueda configurarse a través de conductas omisivas, debemos partir por la postura de Abanto (2003), quien sostiene que «el agente, necesariamente y de manera activa, debe concertar o ponerse de acuerdo con los interesados en negociar con el Estado» (p. 264).

En el mismo sentido García (2008), por su parte, afirma que «la conducta de un funcionario público de un comité de selección de no hacer nada ante una licitación amañada por otros miembros, no es equiparable a una concertación con los interesados que exigen el tipo penal» (p. 51); asimismo, con relación a las conductas de omisión propia, sostiene que «aquel funcionario público que omite podrá ser imputado del delito de omisión de denuncia $u$ omisión de deberes funcionales, pero no por el delito de colusión» (p. 51). Explicando esta posición, Castillo (2017) sostiene que:

La vigencia del principio de legalidad y la naturaleza del delito de colusión como un delito de medios típicos referenciados obliga a considerar a la infracción como limitada y circunscrita a ciertas formas comisivas que excluyen de su radio de acción a ciertas acciones, y, sobre todo, omisiones. La finalidad de la norma penal no es prohibir cualquier conducta que puede cometerse dentro de un proceso de contratación estatal que se sigue en una entidad pública, sino más bien —y he aquí la importanciase busca prohibir una forma de acción considerada como la más grave: concertar, y que implica una absoluta distorsión de la contratación pública a fin de direccionar el 
proceso en beneficio de un postor o favorecerlo luego de haberse adjudicado el contrato estatal. (p. 310).

Planteando una justificación, por su parte, Pariona (2017) sostiene que «el sentido social y normativo del verbo concertar denota una conducta eminentemente activa por la que un funcionario público y un particular se ponen de acuerdo para defraudar al Estado en un contrato estatal» (p. 112).

Finalmente, compartiendo el mismo criterio, Salinas (2019) cuestiona la sentencia condenatoria que fue confirmada en la ejecutoria suprema del 11 de octubre del 2005, donde se estimó la tesis incriminatoria de la Fiscalía que calificó erróneamente una típica conducta de omisión de deberes funcionales como delito de colusión.

En conclusión, es de advertirse en esta postura, la equiparación de la conducta típica que configura el delito de colusión, esto es, la concertación, con aquellas conductas que pueden desplegarse como consecuencia del acuerdo colusorio, debiendo encontrar aún los fundamentos necesarios para poder negar la existencia de una correlación entre la conducta comisiva del delito en cuestión con una modalidad omisiva.

\subsection{Posición de la Jurisprudencia:}

\section{a) Tesis a favor}

Será importante hacer un análisis de tres pronunciamientos de la Corte Suprema donde sus miembros han aceptado la concurrencia de una comisión por omisión en este delito, e identificar cuáles son los fundamentos que sustentan dicha postura.

Así, en el primero de ellos que versa sobre la adquisición de equipos de cómputo por parte de la Municipalidad Provincial de Mariscal Nieto, con relación a uno de los imputados que desempeñó el cargo de administrador general de dicha entidad, se estableció que por su condición:
Se encontraba en la obligación de supervisar las acciones correspondientes al sistema de abastecimiento, evidenciándose con su inacción no solo su voluntad de infringir sus deberes inherentes al cargo que desempeñaba, sino además el concierto de voluntades, al permitir la suscripción de contratos con anterioridad al proceso de adjudicación directa. (Corte Suprema, R.N. N. ${ }^{\circ}$ 278-2005)

Donde se aprecia que no se efectuó un análisis propiamente de si la conducta omisiva pudo corresponder a una conducta comisiva del delito de colusión, criterio que se aprecia también en otro pronunciamiento de la Corte Suprema, coetáneo al anterior, donde del mismo modo frente a un caso típico de delito de omisión de deberes funcionales se estima acreditada un acto colusorio mediante una modalidad omisiva, así, se estableció que:

Dada su calidad de profesionales de la ingeniería tenían la obligación de verificar que en realidad la obra se encontrara operativa y ejecutada conforme a lo establecido en el correspondiente expediente técnico, situación que permite inferir la concertación entre los encausados y el contratista a fin de hacer aparecer como cabalmente ejecutada una obra que no se ajustó a los acuerdos previamente adaptados con la entidad contratante, encontrándose acreditada de esta manera la culpabilidad de los recurrentes. (Corte Suprema, R.N. N. ${ }^{\circ}$ 648-2005)

Finalmente, en uno de los casos más sonados en la ciudad de Cusco, donde se condenó a un presidente regional y varios funcionarios, así como a terceros intervinientes como proveedores, la Corte Suprema estableció igualmente responsabilidad penal por el delito de colusión a través de la verificación de conductas omisivas respecto al cumplimiento de sus funciones por parte del titular de pliego, indicándose que:

En el presente caso correspondía al Presidente Regional del Cusco velar por el patrimonio de la entidad pública de la que 
era titular, que entregó al contratista para la ejecución del mantenimiento de los trece tramos carreteros, [...]; sin embargo, pese a tener conocimiento de las subcontrataciones realizadas por Joel José Salazar Salcedo y que ninguno de los funcionarios o servidores del Gobierno Regional -Gerencia de infraestructura a cargo de Guido Gallegos Cáceres o el Supervisor de Obra Daniel Morgan Merino Yépez- asumían medidas correctivas al respecto, emitió la Resolución Ejecutiva Regional que aprobó la intervención económica de la obra, con el que consentía el actuar ilícito del contratista y sus socios - Nelly Palomino Chacca, Alex Milenko Cárdenas Tresierra-, permitiendo que estos se apropiaran indebidamente de los fondos públicos. (Corte Suprema, R.N. N. ${ }^{\circ}$ 77-2012)

En este orden de ideas, de los tres casos expuestos, más allá de la determinación de la posición de garante de los funcionarios públicos, que bien puede darse por cierta, no se ha podido encontrar un análisis referido a la verificación de la cláusula de correspondencia, sino, tan solo la invocación de probanza de un acuerdo colusorio a través de conductas omisivas.

\section{b) Tesis en contra}

Contrariamente a lo anterior, la Corte Suprema ha tenido en cantidad una mayor producción jurisprudencial adoptando una posición contraria a aceptar la comisión del delito de colusión mediante conductas omisivas.

Así, un primer pronunciamiento de la Corte Suprema sentenció que «la concertación solo puede realizarse de manera comisiva y no omisiva, conforme con la pretensión del Ministerio Público, por tanto, la omisión de denunciar actos ilegales de un funcionario colega no es, por sí misma, una concertación» (Corte Suprema, R.N. N. ${ }^{\circ}$ 1167-2010); sin embargo, es de advertir la ausencia de razones para afirmar que la concertación se ha de materializar únicamente mediante actos comisivos.
Luego, tenemos criterios jurisprudenciales que identificaron las conductas como delito de omisión de actos funcionales, más no, así como conductas colusorias, así en un caso similar la Corte Suprema determinó que:

Si bien el señor fiscal superior sustentó los cargos en este extremo, al señalar que el encausado Monteverde Pomareda titular del Pliego de la Municipalidad Provincial de Tarma, no supervisó ni controló a su co procesado Cortez Porras —Director Municipal-, tales cargos resultan ajenos al núcleo rector del delito en comento, lo que en todo caso configuraría una irregularidad administrativa que escapa a la esfera judicial penal. (Corte Suprema, R.N. N. ${ }^{\circ} 440-2011$ )

En el mismo sentido, se sostuvo que «si bien la imputación fiscal estriba en que estos habrían omitido e incumplido acciones tendientes a asegurar el cumplimiento estricto de las condiciones pactadas, [...], dicha conducta resulta ser ajena al delito de colusión» (Corte Suprema, R.N. N. ${ }^{\circ}$ 2456-2012), y en un caso similar se concluyó que «resulta irrelevante para la configuración del tipo penal que el funcionario posea facultades de control posterior o de denunciar las irregularidades que pudieran detectarse, pues la omisión de estas obligaciones no constituye actos de contribución a la actuación defraudatoria» (Corte Suprema, R.N. N. ${ }^{\circ}$ 118-2013).

En otro pronunciamiento, se logró justificar la falta de concurrencia de la cláusula de correspondencia en una modalidad omisiva del delito en cuestión, así se precisó que:

Debe realizarse de manera comisiva, pues no es posible una concertación o colusión defraudatoria mediante una omisión, al requerir dichos actos de ciertas maniobras a ejecutar por parte del sujeto activo, de manipular datos, sobrevaluar los precios ofertados así como las sumas acordadas, entre otros (Corte Suprema, R.N. N. ${ }^{\circ}$ 3551-2014); así también se concluyó en un caso similar que tales actos no pueden constituir por sí 
mismos, un acto de concertación, que por su naturaleza requiere la comisión de alguna acción, y no un dejar de hacer. (Corte Suprema, R.N. N. ${ }^{\circ}$ 2182-2014)

De esta forma, en los pronunciamientos que se sitúan en contra de aceptar una modalidad omisiva en el delito de colusión se ha verificado la distinción realizada entre una conducta típica de delito de omisión de deberes funcionales, que por su naturaleza corresponde a un delito de omisión propia, por ser delito de mera actividad y estar tipificada en la ley penal, y por tanto su relación excluyente con una comisión por omisión; y, por otro lado, se apreciaron algunas justificaciones para negar la posibilidad de correspondencia entre una omisión con el acto comisivo propio del delito de colusión, lo cual nos da mayores luces a efectos de adoptar una posición frente a esta problemática.

\subsection{Análisis en los delitos de omisión propia}

Recordemos que las peculiaridades de esta modalidad delictiva radican en su naturaleza de delitos de mera actividad al contener un mandato previo, regulado en la ley penal, sin ser parte de sus elementos la verificación de un resultado lesivo (Villavicencio, 2006)

De esta forma, resulta sencillo afirmar que no será posible invocar esta modalidad delictiva en el delito de colusión agravada, dado que esta última precisa de la concurrencia de un resultado lesivo, esto es, la defraudación del Estado, a través de una concertación entre el funcionario y el particular, por lo tanto, aunque pueda parecer estar de más esta afirmación, ha de rechazarse liminarmente la aplicación de una conducta de omisión propia en la modalidad agravada del delito de colusión.

Ahora bien, con relación a la denominada colusión simple, corresponde adoptar los fundamentos de la Corte Suprema, que en resumidas cuentas sostuvo que el delito de colusión, sin distinguirse modalidad, requiere por su propia naturaleza la realización de alguna acción, mas no así un dejar de hacer, debiendo precisar que la conducta típica que configura esta modalidad de delito de colusión viene a ser el verbo rector "concertar», el mismo que precisará de la conjunción de voluntades entre el funcionario público y el tercero.

En efecto, la conjunción de voluntades a la que hace referencia el verbo rector de esta modalidad del delito de colusión nos conlleva a afirmar que no podrá arribarse a este acuerdo de voluntades mientras falte una acción que busque generar y/o acepte el acuerdo colusorio, sea que este surja del mismo funcionario público con vinculación funcionarial, o del particular que participa en el proceso de contratación estatal, o bien pueda surgir de ambos, y de igual forma, la aceptación del ofrecimiento efectuado; por lo tanto, al igual que la modalidad agravada, en esta modalidad simple tampoco ha de aceptarse la verificación del delito en cuestión a través de una conducta de omisión propia.

\subsection{Análisis en los delitos de omisión impropia}

Cuestión distinta será respecto a la posibilidad de que estas conductas que son consecuencia de la concertación puedan materializarse a través de una omisión impropia. Al respecto debemos partir por el hecho de que la omisión impropia se equipara a un delito de resultado, dado que precisa de la afectación efectiva del bien jurídico tutelado; por lo que si bien puede configurarse independientemente a cada conducta que como consecuencia del acuerdo colusorio pueda configurar a su vez un determinado delito de comisión al tener un resultado, no será posible por sí misma que los resultados de estos delitos independientes que surgen como consecuencia de la concertación, puedan ser precisamente equiparables a la existencia de un acuerdo colusorio, dado que además, de las modalidades de este delito, la colusión simple es un delito de mera actividad.

Así, en el delito de colusión simple liminarmente se deberá descartar la posibilidad de que una figura de omisión impropia pueda 
configurar la conducta típica de este delito, que, como se explicó en su momento, constituye un delito de mera actividad, por tanto, al no precisar de la verificación de un resultado, no podría aceptarse una conducta de omisión impropia que contrariamente requiere que exista un resultado lesivo.

El problema surge en la modalidad agravada del delito de colusión, que, para su configuración, exige un resultado: defraudar al Estado; el cual también se presenta en la omisión impropia. Al respecto, como ya se ha concluido, en el delito de colusión en su modalidad agravada, la sola defraudación no configura por sí misma el delito en cuestión, sino, que la misma deberá realizarse a través de un medio comisivo: la concertación.

En este entendido, será necesario analizar si se cumplen los elementos de la omisión impropia en este tipo de delito, esto es, la posición de garante y la cláusula de correspondencia.

\section{a) Verificación de la posición de garante}

Como se explicó en la primera parte de este análisis, una persona se encuentra en una posición de garante cuando asume un determinado deber jurídico que le obliga evitar que se genere un resultado típico.

En el delito que nos ocupa, de acuerdo a la teoría formal del deber jurídico, encontraríamos como principal fuente del deber jurídico del funcionario público a la ley, sea por ejemplo la Ley Orgánica de Municipalidades, la Ley General del Sistema Nacional de Presupuesto, o el Reglamento de la Ley de Contrataciones y Adquisiciones del Estado, o las directivas aprobadas por el Ministerio de Economía y Finanzas, vale decir, entendiendo a la ley desde un punto de vista amplio; y en algunos casos al contrato, dependiendo el régimen y tipo de cargo que este ha de asumir; por otro lado, con relación al fundamento que sustenta este deber jurídico, conforme a la denominada teoría material, podría encontrar sustento en los deberes de custodia, cuando la ley o el contrato otorgan la función de proteger un determinado bien jurídi- co, y en forma similar, encontraríamos sustento en los deberes se aseguramiento, cuando se otorgue la función de supervisar una fuente de peligro, cuando se trate de supervisar, por ejemplo, las actividades de otro funcionario público, sea por delegación o jerarquía.

El primer punto que deberá verificarse precisamente serán las funciones que ostente el sujeto, a mérito del cual se determinará su competencia funcional específica, o llamada también vinculación funcionarial, a mérito del cual se delimita el ámbito de las competencias del funcionario público, y a mérito del cual «tiene la función específica de intervenir en los contratos públicos y la autoridad para llevarlos a cabo y comprometer el patrimonio estatal» (Pariona, 2017, p. 33); de ahí que en la fórmula legislativa del tipo penal se haya empleado el término «por razón de su cargo» al hacer referencia a la intervención del sujeto activo.

Una vez identificado el ámbito de competencia del funcionario público, se podrá afirmar la exclusión de imputación sobre aquellos actos que estén fuera de su vinculación funcionarial, cuando estos sean de responsabilidad de otros funcionarios o simplemente no se traten de deberes específicos.

Sin embargo, pueden existir cierto tipo de deberes que pueden resultar aparentemente subsumibles como deberes jurídicos que definan una posición de garante del funcionario público en el delito de colusión, así, tenemos en primer término aquellos deberes generales que ostentan los titulares de las entidades, llámese alcaldes, presidentes regionales, administradores, entre otros; luego, tenemos aquellos deberes de supervisión de funcionarios de menor nivel jerárquico o a mérito de actos de delegación de atribuciones, y finalmente aquellos deberes que ostentan los miembros de órganos colegiados.

\section{i) Deberes generales de titulares de la entidad}

Sobre el particular, se aprecian aquellas funciones que no son específicas, 
sino más bien generales, que pueden atribuirse a titulares de entidades, como pueden ser los alcaldes o presidentes regionales, a quienes por ejemplo se les imputa responsabilidad por el manejo presupuestario de su organización (Ley General del Sistema Nacional de Presupuesto, 2004), luego, a falta de intervención directa en los procesos de selección de estos funcionarios, como es, el otorgamiento de la buena pro, la formulación de los términos de referencia, entre otros, es que se pretende atribuir responsabilidad penal en este delito por una falta de supervisión de las actividades de otros funcionarios de menor jerarquía.

Al respecto, nuestra Corte Suprema ya ha establecido que esta falta de supervisión no puede subsumirse en el verbo rector del delito de colusión (Corte Suprema, R.N. N. ${ }^{\circ} 440-2011$ ); así, estos titulares de pliego no actúan por razón de su cargo, por lo que no ostentan una posición de garante, la misma que «supone siempre el deber y obligación legal de intervenir para evitar el resultado típico» (Pariona, 2017, p. 116), siendo que dicha condición la han de asumir aquellos funcionarios que de acuerdo a ley ostenten la función de intervenir en estos procesos de selección.

Así, conforme se evidencia, la configuración de este delito se establecerá a raíz de la verificación de una concertación entre el funcionario con vinculación funcionarial y el tercero ajeno a la administración, siendo que la labor de supervisión omitida que se atribuye al titular deviene en un contexto temporal posterior, razón por la cual podría, de ser el caso, justificar la imposición de responsabilidades administrativas, o por un delito de omisión de deberes funcionales, quedando descartada la imputación del delito de colusión al no verificarse la existencia de una posición de garante, sin necesidad de ingresar al ámbito de verificación de la concurrencia de la cláusula de correspondencia.

\section{ii) Deberes de supervisión}

Es recurrente en la casuística encontrar supuestos donde un funcionario público, que ocupa un puesto de jerarquía en la administración pública, no cumple con realizar ciertos actos de control y supervisión sobre otro funcionario que se encuentra en subordinación y como consecuencia de ello se produce una concertación dolosa, o cuando esta es desplegada por un funcionario público que recibió funciones a mérito de una delegación.

Es evidente que la falta del deber de supervisión, configura una omisión de un deber, que, si se configura a título de dolo, se subsume en los alcances del delito de omisión de funciones; en igual sentido, se puede afirmar el mismo criterio en lo concerniente a la delegación, que según nuestra doctrina y legislación no implica el abandono de la situación de vulnerabilidad del bien jurídico, pudiendo afirmar válidamente que sí nos encontramos en la posición de garante por la concurrencia de un deber jurídico específico, es decir, por la vinculación funcionarial del sujeto.

Por lo tanto, deberá analizarse si dicha conducta omisiva puede corresponder a la realización de una conducta comisiva que genere el resultado lesivo, es decir verificar si se cumple la cláusula de correspondencia.

\section{iii) Deberes en órganos colegiados}

Castillo (2017), sostiene que, «existen funcionarios que, a mérito de su función, pueden tomar conocimiento de determinadas conductas de otros 
funcionarios, y dentro de este contexto, tomar conocimiento de actos colusorios» (p. 298).

Situación especial merece ser tratada cuando deberes jurídicos son ejercidos no solo por un único funcionario público, sino, por un órgano colegiado, quienes han de tomar decisiones en conjunto, al respecto, es posible que todos los miembros concierten con un tercero interesado, no dejando dudas de la configuración del verbo rector del delito de colusión, sin embargo, el problema surge cuando solo uno o alguno de ellos despliegan esta concertación, y si dicha conducta comisiva puede imputarse al miembro que, teniendo conocimiento del acuerdo colusorio de los demás, guarda silencio, y permite que los demás miembros defrauden a la entidad mediante la concertación con el tercero interesado, pudiendo haber comunicado el hecho a las autoridades correspondientes.

Sobre el particular, no cabe dudas en afirmar que dicho funcionario, miembro del órgano colegiado, ostenta una posición de garante, pues en efecto, al igual que los otros miembros que sí han concertado, mantiene un deber jurídico especial, a mérito del cual interviene en el proceso de contratación, sin embargo, al igual que en el caso de los deberes especiales de supervisión, se tendrá que analizar si el silencio o inacción en que incurre este miembro puede corresponder a la realización de una concertación, situación que se analizará en la cláusula de correspondencia.

\section{b) Verificación de la cláusula de correspon- dencia}

Se ha explicado que la comisión por omisión no requiere solamente de la existencia de una posición de garante del sujeto, o que el re- sultado lesivo pueda imputarse a la omisión del obligado solamente a través de una causalidad hipotética, sino que deberá analizarse si esta omisión puede corresponder a la realización de una conducta comisiva.

De esta forma, se estableció que la conducta comisiva que el legislador ha tipificado como delito de colusión, viene a ser la concertación, sea que nos encontremos en la modalidad simple o agravada. La concertación para defraudar o la defraudación a través de concertación, respectivamente, precisará que el sujeto activo realice la conducta establecida como verbo rector, esto es, concertar; dejando en claro que en la modalidad agravada la conducta no se materializará a través de cualquier defraudación, sino solo aquella que se haya generado mediante una concertación.

Ahora bien, como se ha analizado, la concertación se materializa a través del encuentro o llamada también conjunción de las voluntades declaradas por el funcionario público y el tercero interesado, razón por la que se considera a este delito como uno de encuentro o de convergencia (Castillo, 2017), donde será necesaria la intervención de ambos para formar el denominado acuerdo colusorio.

En este orden de ideas, corresponde analizar si una determinada conducta omitida, a razón de la posición de garante en la que se encuentra un sujeto, puede corresponder a la realización de la modalidad comisiva del tipo penal, habiéndose identificado dos supuestos de omisión que podrían corresponder al verbo rector de concertar, esto es, la omisión de supervisión y la omisión de denunciar.

La verificación de la cláusula de correspondencia, en algunos tipos penales no resulta ser problemática, así, en el delito de homicidio, podrá identificarse que, al ser la conducta comisiva «matar», esta puede equipararse a la conducta omisiva «dejar morir», validando la concurrencia de esta cláusula de correspondencia, pues no cabe duda que nos encontramos frente un delito monosubjetivo, es decir, 
que la conducta es realizada por un solo autor; sin embargo, el problema surge cuando se trata de un delito plurisubjetivo, donde se requerirá el encuentro de dos voluntades autónomas para configurar la conducta, como precisamente ocurre en el delito que venimos analizando.

Habiendo identificando la conducta comisiva del delito de colusión como «concertar» definitivamente no podrá verificarse su correspondencia mediante una conducta omisiva de «dejar concertar», toda vez que el sujeto solo podrá concertar cuando su voluntad se encuentre con otra voluntad autónoma, faltando precisamente dicha voluntad si no existe una acción e imposibilitando que exista un encuentro con la otra voluntad autónoma desplegada por el tercero interesado que permita, precisamente, concertar.

Teniendo clara esta idea, nos es posible analizar ahora sí, la omisión en el cumplimiento de un deber específico de supervisar la actividad de un subordinado o del que actúa por delegación, puede corresponder a la conducta comisiva "concertar», permitiéndonos negar en consecuencia la verificación de la cláusula de correspondencia de esta conducta omisiva, así, convenimos con Castillo (2017). quien concluye que ]el no supervisar no implica que se cometa colusión, y no necesariamente una conducta dolosa, sino solo la infracción de un deber extrapenal» (p. 304), por lo que el incumplimiento de un deber de supervisión no podrá configurar, a mérito de una omisión impropia, el delito de colusión.

Por otro lado, lo mismo ocurrirá en la conducta omisiva al interior de un órgano colegiado por parte del miembro que tomó conocimiento del acuerdo colusorio de sus demás integrantes, pues al igual que en el caso de la omisión de un deber de supervisión, el silencio del funcionario que conoce un hecho delictivo no podrá corresponder a la exteriorización de una voluntad que al encontrarse con otra voluntad autónoma de un tercero interesado puedan formar la conducta tipificada en el delito de colusión: concertar.
En este sentido, esta omisión de supervisar o de denunciar será sancionada por la sola razón de no haber actuado, es decir, por la sola razón de no haber supervisado al subordinado o al que actúa por delegación, o por no haber denunciado el hecho delictivo que ha conocido, sin necesidad de verificar la configuración de un resultado lesivo para la entidad, estableciéndose la tipicidad de esta conducta como delito de omisión propia, vale decir, como delito de omisión de deberes funcionales y omisión de denuncia, previstos en los artículos 377 y 407 del Código Penal respectivamente, o podrán ser pasibles de responsabilidad administrativa por el incumplimiento de dichas funciones, frente al resultado defraudatorio producido en agravio de la entidad, e incluso por esto último responsabilidad de índole civil; mas no así podrá admitirse que estas conductas puedan ser sancionadas a mérito de una comisión por omisión, como delito de colusión.

\section{CONCLUSIONES}

De todo el recorrido realizado en el presente trabajo, hemos podido establecer varias ideas que puntualmente permiten fundamentar la adopción de una postura concreta frente a la problemática expuesta.

En primer lugar, se ha señalado que la conducta comisiva del delito de colusión se realiza a través de su verbo rector "concertar», sea que nos encontremos frente a su modalidad simple o agravada, en la primera se requerirá la sola concertación, y en la segunda la defraudación mediante, necesariamente, una concertación, y en este sentido se ha establecido que al tratarse de un delito pluriofensivo de encuentro, la conducta comisiva de «concertar» se realizará a través del encuentro de dos voluntades autónomas, la del funcionario público que interviene por razón de su cargo y la del tercero interesado.

En segundo lugar, hemos visto que en la modalidad de omisión propia no podrá verificarse la modalidad simple del delito de colusión, 
pues si bien existiría una relación con la falta de verificación de un resultado, la imposibilidad se centrará en la necesidad de conducta comisiva para formar el verbo rector «concertar«, lo que deviene en inviable en conductas omisivas, criterio que también es de aplicarse en la modalidad agravada de este delito, el mismo que exige también el despliegue de una conducta comisiva, postura que ha sido establecido de manera mayoritaria en nuestra jurisprudencia.

En tercer lugar, con relación a la modalidad de omisión impropia, se podrá descartar liminarmente su concurrencia en el delito de colusión simple al ser un delito de mera actividad, el cual se ha de configurar con la sola verificación de la conducta, sin ser necesario que se haya producido un resultado lesivo.

En cuarto lugar, se ha identificado la mayor incidencia de la problemática en la posibilidad de que se configure el delito de colusión en su modalidad agravada mediante una comisión por omisión, pues en la misma existe un resultado lesivo que podría atribuirse a una conducta omisiva del sujeto que se encuentra en posición de garante de evitar la producción de un resultado lesivo y que puede corresponder a la realización de una conducta comisiva.

De esta forma, con relación al primer elemento consistente en la posición de garante, se han identificado los deberes de supervisión de las actividades de subordinados o de quienes ostentan funciones delegadas, y el deber de denunciar hechos delictivos que se hayan conocido al interior de un órgano colegiado, donde sí se verifica la existencia de una posición de garante frente a resultados lesivos que defrauden a la entidad.

Sin embargo, se ha podido establecer que la conducta omisiva en estos deberes no cumple con el segundo elemento de la omisión impropia, vale decir, con la cláusula de correspondencia, toda vez que las conductas omisivas de «no supervisar» y de «no denunciar» no pueden corresponder a la realización de una conducta comisiva de «concertar» en la medida que esta última requiere, para su configuración, que la voluntad autónoma del funcionario público tenga un encuentro con aquella del tercero interesado, encuentro que no podrá verificarse ante la ausencia de la voluntad autónoma del sujeto con posición de garante.

Por lo tanto, la omisión de los deberes de supervisión y de denunciar podrán ser sancionadas como delito de omisión de deberes funcionales u omisión de denuncia, tipificados en los artículos 377 y 403 del Código Penal respectivamente, vale decir, como delitos autónomos de omisión propia, y respecto al resultado lesivo podrían ser pasibles de responsabilidad administrativa o de índole civil, empero no podrán ser sancionadas dichas omisiones como delito de colusión, en su modalidad agravada, a mérito de una omisión impropia.

\section{REFERENCIAS BIBLIOGRÁFICAS}

ABANTO M. (2003). Delitos contra la administración pública en el código penal peruano (Segunda edición). Palestra Editores.

CÁcEREs R. (2016). El delito de colusión. aspectos sustantivos y probatorios, en delitos contra la administración pública cometidos por funcionarios públicos (Primera edición). Gaceta Jurídica.

Castillo J. (2017). El delito de colusión (primera edición). Instituto Pacífico.

García P. y CAStiLlo J. (2008). El delito de colusión. (Primera edición). Editora Jurídica Grijley.

Hugo J. y Huarcaya B. (2018). Delitos contra la administración pública - análisis dogmático, tratamiento jurisprudencial y acuerdos plenarios (Primera edición). Gaceta Jurídica.

JESCHECK H. y WEIGEND T. (2014). Tratado de derecho penal, parte general (Traducción de OImedo M.; Primera edición). Instituto Pacífico (Originalmente publicado en 1996).

Mezger E. (1958). Derecho penal. libro de estudio. parte general (Primera edición). Editorial Bibliográfica Argentina S.R.L. 
MuÑOz F. y GARCíA M. (2002). Derecho penal. parte general (Quinta edición). Tirant Lo Blanch.

PARIONA R. (2017). El delito de colusión (Primera edición). Instituto Pacífico.

Parma C. (2017). Teoría del delito 2.0. (Primera edición). Adrus D\&L Editores S.A.C.

Real Academia Española (s.f.). Colusión. En: Diccionario de la Lengua Española. Recuperado el 31 de octubre del 2020. https://dle.rae. es/colusion? $\mathrm{m}=$ form

Real Academia Española (s.f.). Concertar. En: Diccionario de la Lengua Española. Recuperado el 31 de octubre del 2020. https://dle. rae.es/concertar? $\mathrm{m}=$ form

REÁteguI J. (2015). Delitos contra la administración pública en el código penal (Primera edición). Jurista Editores.

RoJas F. (2002). Delitos contra la administración pública (Tercera edición). Editora Jurídica Grijley.

SALINAS R. (2019). Delitos contra la administración pública (Quinta edición). Editorial lustitia.

SILVA J. (2004). Estudios sobre los delitos de omision (Primera edición). Editora Jurídica Grijley.

Villavicencio F. (2006). Derecho penal. Parte general (Primera edición). Editora Jurídica Grijley.

\section{Referencias jurídicas}

Código Penal de la Nación Argentina. (1991) http://servicios.infoleg.gob.ar/infoleglnternet/anexos/15000-19999/16546/texact.htm

Código Penal de la República de Chile. (1874) ht t ps: / / w w w.bcn.cl/leychile/ navegar?idNorma $=1984$

Código Penal Peruano. (1991) http://spij.minjus.gob.pe/content/publicaciones_oficiales/img/CODIGOPENAL.pdf

Decreto Legislativo del Sistema de Defensa Jurídica del Estado. Decreto Legislativo N. 1068 (2008). Diario oficial El Peruano. https://www. minjus.gob.pe/wp-content/uploads/2014/08/ Decreto-Legislativo-1068.pdf

Decreto Legislativo que modifica el Código Penal y el Código de Ejecución Penal a fin de establecer y ampliar el plazo de duración de la pena de inhabilitación principal, e incorporar la inhabilitación perpetua para los delitos cometidos contra la Administración Pública, y crea el registro único de condenados inhabilitado. Decreto Legislativo $N^{\circ} 1243$ (2016). Diario oficial El Peruano. https://busquedas. elperuano.pe/download/url/decreto-legislativo-que-modifica-el-codigo-penal-y-el-codigo-decreto-legislativo-n-1243-1444966-1

Expediente N. ${ }^{\circ}$ 00017-2011-PI/TC (2012), 03 de mayo del 2012.

Ley General del Sistema Nacional de Presupuesto. Ley N. ${ }^{\circ} 28411$ (2014). Diario oficial El Peruano. http://transparencia.mtc.gob.pe/ idm_docs/normas_legales/1_0_31.pdf

Ley que incorpora la pena de multa en los delitos cometidos por Funcionarios Públicos. Ley N. 30111 (2013). Diario oficial El Peruano. https://busquedas.elperuano.pe/normaslegales/ley-que-incorpora-la-pena-de-multa-en-los-delitos-cometidosley-n-30111-1019287-1/

Ley que modifica artículos del Código Penal referidos a la sanción del funcionario 0 servidor que defrauda al Estado. Ley N. ${ }^{\circ}$ 26713 (1996). Diario oficial El Peruano. https://leyes.congreso.gob.pe/documentos/ Leyes/26713.pdf

Ley que modifica el Código Penal respecto de los delitos contra la Administración Pública. Ley N. 29703 (2011). Diario oficial El Peruano. http://cdn01.pucp.education/idehpucp/wpontent/uploads/2017/06/27215812/normanac076.pdf

R.N. N. ${ }^{\circ} 278-2005$ (2005), 10 de mayo del 2005, Sala Penal Permanente.

R.N. N. ${ }^{\circ}$ 648-2005 (2005), 11 de octubre del 2005, Sala Penal Permanente. 
R.N. N. ${ }^{\circ} 1296-2007$ (2007), 12 de diciembre del 2007, Segunda Sala Penal Transitoria.

R.N. N. ${ }^{\circ} 1167-2010$ (2013), 24 de julio del 2013, Sala Penal Transitoria.

R.N. N. ${ }^{\circ}$ 440-2011 (2012), 01 de febrero del 2012, Sala Penal Permanente.

R.N. N. ${ }^{\circ}$ 77-2012 (2012), 22 de agosto del 2012, Sala Penal Transitoria.
R.N. N. ${ }^{\circ}$ 2456-2012 (2013), 11 de abril del 2013, Sala Penal Transitoria.

R.N. N. ${ }^{\circ} 118-2013$ (2013), 22 de noviembre del 2013, Sala Penal Transitoria.

R.N. N. ${ }^{\circ} 2182-2014$ (2015), 16 de abril del 2015, Sala Penal Transitoria.

R.N. N. ${ }^{\circ}$ 3551-2014 (2015), 17 de abril del 2015, Sala Penal Permanente. 